\title{
Google search behavior for meningitis and its vaccines: an infodemiological study
}

\author{
John Angelo Luigi S. Perez ${ }^{1}$, Adrian I. Espiritu ${ }^{2,3} \mathbb{B}$ and Roland Dominic G. Jamora ${ }^{1,3^{*}} \mathbb{0}$
}

\begin{abstract}
Background: The internet has made significant contributions towards health education. Analyzing the pattern of online behavior regarding meningitis and vaccinations may be worthwhile. It is hypothesized that the online search patterns in meningitis are correlated with its number of cases and the search patterns of its related vaccines.

Methods: This was an infodemiological study that determined the relationship among online search interest in meningitis, its worldwide number of cases and its associated vaccines. Using Google Trends ${ }^{\text {TM }}$ Search Volume Indices (SVIs), we evaluated the search queries "meningitis," "pneumococcal vaccine," "BCG vaccine," "meningococcal vaccine" and "influenza vaccine" in January 2021, covering January 2008 to December 2020. Spearman rank correlation was used to determine correlations between these queries.

Results: The worldwide search interest in meningitis from 2008 to 2020 showed an average SVI of $46 \pm 8.8$. The most searched topics were symptoms, vaccines, and infectious agents with SVIs of 100, 52, and 39, respectively. The top three countries with the highest search interest were Ghana, Kazakhstan, and Kenya. There were weak, but statistically significant correlations between meningitis and the BCG $(\rho=0.369, p<0.001)$ and meningococcal $(\rho=0.183, p<0.05)$ vaccines. There were no statistically significant associations between the number of cases, influenza vaccine, and pneumococcal vaccine.
\end{abstract}

Conclusion: The relationships among the Google SVIs for meningitis and its related vaccines and number of cases data were inconsistent and remained unclear. Future infodemiological studies may expand their scopes to social media, semantics, and big data for more robust conclusions.

Keywords: Infodemiology, Meningitis, Vaccines, Google Trends ${ }^{\mathrm{TM}}$

\section{Introduction}

Meningitis is a neurologic emergency that is associated with significant morbidity and mortality. It is the inflammation of the meninges of the brain and spinal cord and may have various etiologies such as infectious, autoimmune, paraneoplastic and even drug-related [1]. It has several risk factors such as human immunodeficiency virus infection, malnutrition, overcrowding, and incomplete vaccinations. The majority of mortalities are

\footnotetext{
*Correspondence: rgjamora@up.edu.ph

${ }^{1}$ Institute for Neurosciences, St. Luke's Medical Center, Quezon City \& Global City, Philippines

Full list of author information is available at the end of the article
}

from infectious meningitis and bacterial meningitis can become rapidly fatal and survivors become severely disabled [1]

Immunization is well-known to be one of the preventive measures against meningitis [1]. Vaccines targeting Hemophilus influenzae type b, Neisseria meningitidis, and Streptococcus pneumoniae have significantly decreased the number of cases of meningitis worldwide [1]. According to the World Health Organization (WHO), vaccinations have reduced the incidence of meningitis in Africa by as much as $58 \%$ and the risk of epidemics has decreased by $60 \%$ [2]. One of the pioneering vaccines developed in collaboration with the WHO, UNICEF, and the Bill \& Melinda Gates Foundation have reduced the 
incidence of meningitis by $94 \%$ after six months in areas with successful vaccination drives [3]. Despite vaccination efforts, meningitis remains a global problem, especially in developing countries and the contiguous African Meningitis Belt [1].

The internet has made a significant contribution towards health education and health-seeking behavior with online news and social media being the most popular sources of information $[4,5]$. In a systematic review, publications utilizing information and communication technologies including the internet generally fell into five categories: a) evaluation of health-related content, b) development and evaluation of health services, c) development and evaluation of health literacy tools, d) interventions to improve health literacy, and e) to promote online health information-seeking behavior [6].

In the case of vaccinations, the internet has significantly affected the volume and quality of information available and in some cases became either facilitator or barrier of health information [7]. Since vaccinations are one of the most important preventive measures against meningitis, analyzing the pattern of online behavior regarding meningitis and vaccinations may be worthwhile. It is hypothesized that the online search patterns in meningitis are correlated with its number of cases and the search patterns of its related vaccines.

This field of studying internet behavior in health is a relatively new concept that may be covered by the field of infodemiology [8]. It is defined as the science of distribution and determinants of information in an electronic medium, specifically the Internet, or in a population, with the ultimate aim to inform public health and public policy [8]. One of the most accessible methods of studying online search patterns is the use of Google Trends ${ }^{\text {TM }}$ (https://trends.google.com). It is a free and publicly available online portal that provides data on Google search queries. It can provide geospatial and temporal patterns on approximately 3 billion search queries daily [9].

The purpose of this study was to determine the associations among online search interest in meningitis, its worldwide number of cases and its associated vaccines. The scope of this study involved vaccine-preventable etiologies of meningitis such as influenza, tuberculosis, meningococcus, and streptococcus.

\section{Methods}

Online interest was measured as search volume index (SVI) provided by the Google Trends ${ }^{\mathrm{TM}}$. SVI is a proprietary index that estimates search activity by taking the proportion of searches of interest relative to the most searched term within a specified geography and timeframe [10]. The SVIs are normalized to geography and time and are then assigned a value from 0 to 100 .

Google Trends ${ }^{\mathrm{TM}}$ was accessed by visiting http://trends. google.com and a combined worldwide search query evaluation for "meningitis", "pneumococcal vaccine", "BCG vaccine", "meningococcal vaccine", and "influenza vaccine" in January 2021. The search was limited from January 2008 to December 2020 and search queries as topics were used instead of freehand keywords. SVI data was then returned by Google Trends ${ }^{\mathrm{TM}}$ and downloaded as Microsoft Excel spreadsheets, version 2101 (Redmond, WA: Microsoft Corp.). The global case numbers of meningitis from 1990 to 2019 were obtained from the Global Health Data Exchange Database (GHDx) as commaseparated values [11]. The figures were generated using Microsoft Word, version 2101.

The non-parametric Spearman rank correlation was used to determine correlations between the SVIs of meningitis, the SVIs of vaccines, and the worldwide number of cases of meningitis. A Durbin-Watson test for autocorrelation was used to determine any seasonality in SVI. All data were using IBM SPSS Statistics for Windows, Version 26.0 (Armonk, NY: IBM Corp). The p-value was set at 0.05 .

\section{Results}

\section{General search interest trends}

Worldwide search interest in meningitis from 2008 to 2020 showed an average SVI of $46 \pm 8.8$. The most related topics searched were symptoms, vaccines, and infectious agents with SVIs of 100,52 , and 39 , respectively. The top five countries with the highest search interest were Ghana, Kazakhstan, Kenya, Paraguay, and Italy (see Table 1). Overall, the trend in search interest for meningitis increased over time with an abrupt drop in May 2020 (see Fig. 1). There were several spikes in SVI in October 2012, February 2016, January 2017, and March 2019.

A search query combining meningitis and its associated vaccines showed generally low search volumes for pneumococcal, meningococcal, and BCG vaccines (see Fig. 1). Search volumes for influenza vaccine were cyclical due to the seasonal nature of the disease. A DurbinWatson test showed a coefficient of 0.598 , indicating positive autocorrelation [12].

\section{The global number of cases of meningitis}

According to the GHDx Database, the number of meningitis cases worldwide as of 2019 was 7,683,539 (10\%). The top three countries with the highest cases were India $(n=2,099,361,15 \%)$, Nigeria $(n=619,660,21 \%)$, and Pakistan ( $\mathrm{n}=401,311,19 \%)$. There was an overall decline in the number of cases starting around 1997. However, the cases increased again in 2016 (see Fig. 2). 
Table 1 Top 50 countries with the highest search volume indices from 2008-2020 and their total cases up to 2019

\begin{tabular}{|c|c|c|c|c|c|}
\hline Country & SVI & Number of cases & Country & SVI & Number of cases \\
\hline 1. Ghana & 100 & 656,602 & 26. Costa Rica & 44 & 1,193 \\
\hline 2. Kazakhstan & 88 & 148,066 & 27. Finland & 44 & 1,625 \\
\hline 3. Kenya & 84 & $1,469,781$ & 28. Ecuador & 42 & 3,439 \\
\hline 4. Paraguay & 82 & 69,311 & 29. Netherlands & 42 & 6,425 \\
\hline 5. Italy & 80 & 92,267 & 30. Australia & 42 & 9,830 \\
\hline 6. Chile & 73 & 57,306 & 31. Dominican Republic & 42 & 5,557 \\
\hline 7. South Africa & 73 & 571,477 & 32. Argentina & 42 & 14,001 \\
\hline 8. Slovenia & 71 & 9,501 & 33. France & 40 & 24,651 \\
\hline 9. Ireland & 68 & 18,993 & 34. Sweden & 40 & 2,687 \\
\hline 10. Brazil & 66 & 160,512 & 35. Hungary & 40 & 2,813 \\
\hline 11. Norway & 66 & 28,609 & 36. Colombia & 40 & 11,644 \\
\hline 12. United Kingdom & 64 & 33,162 & 37. Algeria & 40 & 21,625 \\
\hline 13. New Zealand & 60 & 1,717 & 38. Portugal & 40 & 6,607 \\
\hline 14. United States & 57 & 26,781 & 39. Ukraine & 40 & 32,485 \\
\hline 15. Indonesia & 57 & 150,591 & 40. Switzerland & 40 & 2,142 \\
\hline 16. Denmark & 53 & 3,020 & 41. Romania & 40 & 5,438 \\
\hline 17. Bolivia & 51 & 2,657 & 42. Austria & 37 & 2,414 \\
\hline 18. Jordan & 51 & 9,454 & 43. Germany & 37 & 20,571 \\
\hline 19. Russia & 51 & 76,676 & 44. Czech Republic & 37 & 3,790 \\
\hline 20. Philippines & 51 & 85,124 & 45. Greece & 35 & 3,537 \\
\hline 21. Nigeria & 48 & 619,661 & 46. Slovakia & 35 & 2,244 \\
\hline 22. Belarus & 46 & 6,482 & 47. Venezuela & 35 & 9,131 \\
\hline 23. Belgium & 44 & 3,780 & 48. Egypt & 33 & 60,577 \\
\hline 24. Spain & 44 & 17,813 & 49. Saudi Arabia & 33 & 10,756 \\
\hline 25. Canada & 44 & 4,510 & 50. Morocco & 33 & 24,546 \\
\hline
\end{tabular}
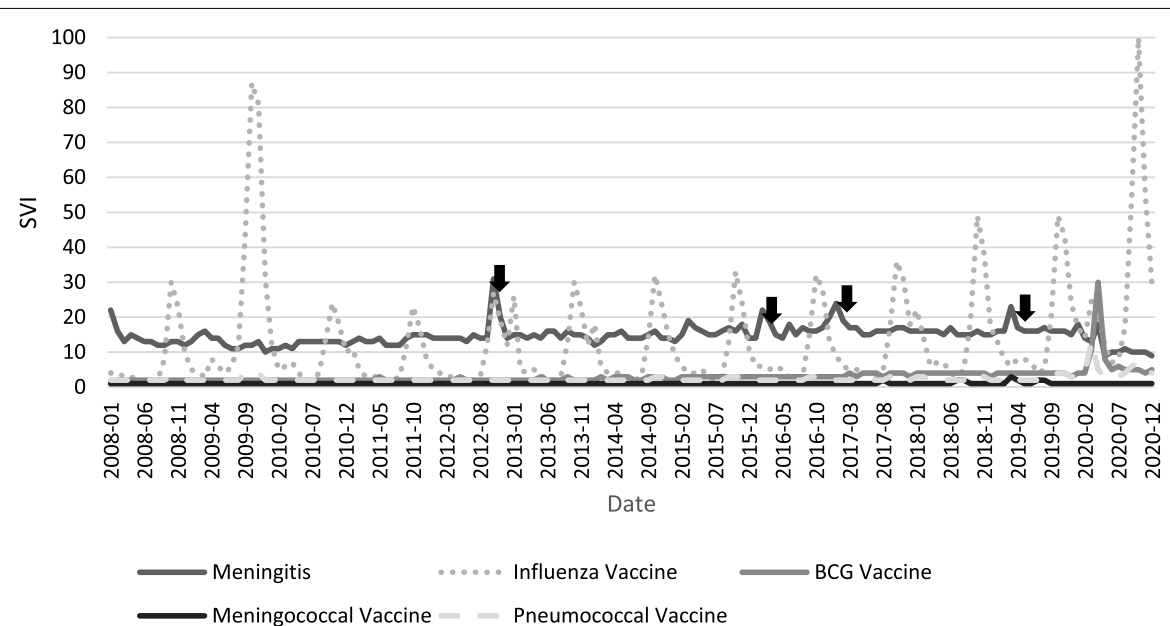

Note: Arrows correspond to peaks in search interest for meningitis.

Fig. 1 Search interests for combined queries on meningitis and its vaccines from 2008 to 2020 
The top searches by country, queries, and rising queries each for meningitis and its vaccines are shown in Table 2. The majority of searches for "meningitis" came from developing countries while a mix of developed and developing countries was searching for its vaccines. The search queries for meningitis were mostly signs and symptoms, while vaccine queries were mostly direct searches. All searches were multi-lingual and had queries in English, Japanese, Italian, Russian, and Greek.

\section{Associations among online search interest in meningitis, its worldwide number of cases and its associated vaccines}

There were weak, but statistically significant correlations between meningitis and the BCG and meningococcal vaccines (see Table 3 ). There was no statistically significant correlation with the number of cases of meningitis.

\section{Discussion}

Our study shows that people who search for meningitis on Google looked for definitions of the disease and its symptoms. The majority of searches came from developing countries. This was consistent with the literature that affirms that the morbidity and mortality burden of meningitis are greater in resource-poor nations [11]. As for the vaccine keywords, the majority searched for general information on the vaccine, the nearest place to get them, and their frequency of administration. Interestingly, most of the searches came from developed countries. This may be due to the lower disease burden of meningitis as shown by their case numbers. Moreover, these nations are already working on prevention rather than acute infection. The pattern of keyword searching that certain countries employ may possibly give public health workers an indication on the current phase of a region in the epidemic stage spectrum. In our study, the countries battling ongoing epidemics are searching for definitions, signs and symptoms, while developed countries are inclined to focus on prevention and are searching for vaccine information, timing and location.

The number of cases of meningitis worldwide showed a generally decreasing trend (see Fig. 2). However, online search interest was slowly increasing (see Fig. 1). This can be due to multiple factors such as increasing awareness of the disease, expanding internet access, and the rising importance of prevention. An exception to this observation was a sudden drop in search interest in May 2020 and this may be due to the coronavirus disease (COVID-19) pandemic dominating search interest globally. The increase in search volumes for influenza, BCG, and pneumococcal vaccines beginning March 2020 were likewise likely related to vaccine interest amidst the COVID-19 pandemic. This underscores again the role of the internet in health-seeking behavior and health education: even if global prevalence decreases, the internet may be used to facilitate and sustain awareness, prevention, and treatment of meningitis. The internet becomes part of the armamentarium of public health both in prevention and management in developed and developing countries.

Google Trends ${ }^{\mathrm{TM}}$ not only provides baseline search data over time, but they also provide insight into sudden spikes in search volume. Several studies have similarly used Google Trends ${ }^{\mathrm{TM}}$ to establish baseline search data and look for changes over time. For example, infodemiological studies using Google Trends ${ }^{\mathrm{TM}}$ on multiple sclerosis [13], status epilepticus [14], and stroke [5] have been performed. In the case of meningitis, there were

\section{Number of Cases}

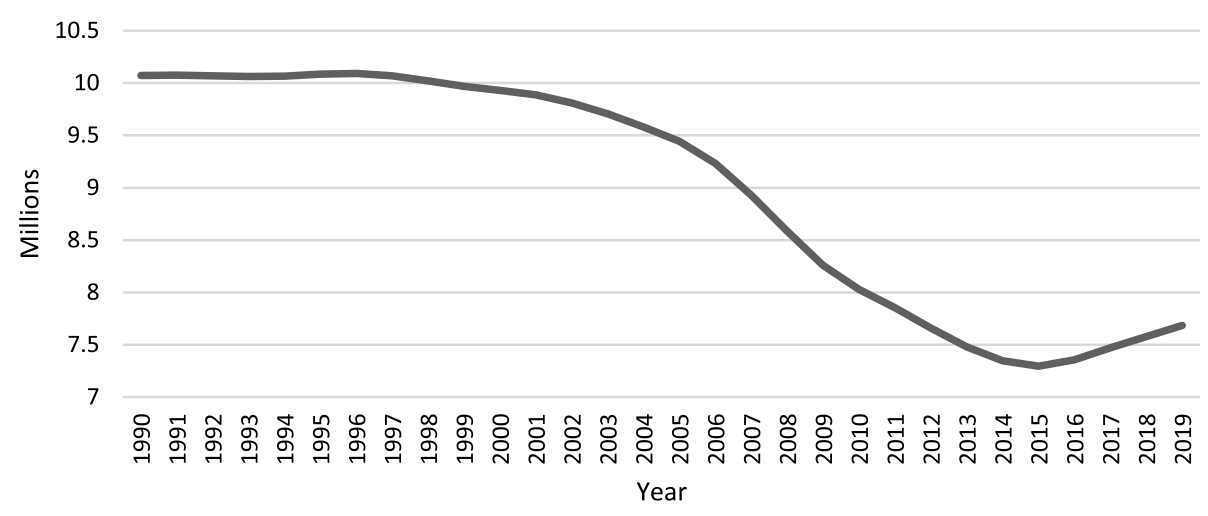

Number of Cases

Fig. 2 Number of meningitis cases globally from 1990-2019 according to the global burden of disease database [6] 
Table 2 Results of search volume analysis and search queries for terms "meningitis," "influenza vaccine," "BCG vaccine," "pneumoccocal vaccine" and "meningoccocal vaccine"

\begin{tabular}{|c|c|c|c|c|c|c|}
\hline Search Term & Country & & Top Queries & & Rising Queries & \\
\hline Meningitis & $\begin{array}{l}\text { Ghana } \\
\text { Kazakhstan } \\
\text { Paraguay } \\
\text { Kenya } \\
\text { Italy }\end{array}$ & $\begin{array}{l}100 \\
93 \\
89 \\
83 \\
79\end{array}$ & $\begin{array}{l}\text { Meningitis } \\
\text { Meningite } \\
\text { Symptoms meningitis } \\
\text { Viral meningitis } \\
\text { Bacterial meningitis }\end{array}$ & $\begin{array}{l}100 \\
27 \\
12 \\
7 \\
6\end{array}$ & $\begin{array}{l}\text { Vacina meningite b } \\
\text { Suntik meningitis } \\
\text { Vaksin meningitis } \\
\text { Gejala meningitis } \\
\text { менингит это }\end{array}$ & Breakout \\
\hline Influenza Vaccine & $\begin{array}{l}\text { Japan } \\
\text { Canada } \\
\text { USA } \\
\text { Finland } \\
\text { Taiwan }\end{array}$ & $\begin{array}{l}100 \\
77 \\
71 \\
67 \\
62\end{array}$ & $\begin{array}{l}\text { Flu } \\
\text { Flu shot } \\
\text { Flu vaccine } \\
\text { インフルエンザ } \\
\text { インフルエンザ 予防 接種 }\end{array}$ & $\begin{array}{l}100 \\
53 \\
21 \\
19 \\
16\end{array}$ & $\begin{array}{l}\text { Flu shot } 2020 \\
\text { Flu shot near me } \\
\text { インフルエンザ 予防接種 } \\
\text { Flu shot } 2019 \\
\text { Flu vaccine } 2020\end{array}$ & Breakout \\
\hline BCG Vaccine & $\begin{array}{l}\text { Japan } \\
\text { Kazakhstan } \\
\text { Nepal } \\
\text { Taiwan } \\
\text { Ukraine }\end{array}$ & $\begin{array}{l}100 \\
98 \\
97 \\
94 \\
92\end{array}$ & $\begin{array}{l}\text { BCG } \\
\text { BCG vaccine } \\
\text { бцж } \\
\text { BCG vacuna } \\
\text { Vacina BCG }\end{array}$ & $\begin{array}{l}100 \\
20 \\
11 \\
7 \\
7\end{array}$ & $\begin{array}{l}\text { コロナ } \\
\text { コロナ BCG } \\
\text { BCG COVID } \\
\text { бцж это } \\
\text { BCG Corona }\end{array}$ & Breakout \\
\hline Pneumococcal Vaccine & $\begin{array}{l}\text { Austria } \\
\text { Portugal } \\
\text { Czechia } \\
\text { Taiwan } \\
\text { Finland }\end{array}$ & $\begin{array}{l}100 \\
78 \\
72 \\
69 \\
68\end{array}$ & $\begin{array}{l}\text { Pneumonia } \\
\text { Prevenar } \\
\text { Pneumococcal } \\
\text { Pneumonia vaccine } \\
\text { Pneumococcal vaccine }\end{array}$ & $\begin{array}{l}100 \\
91 \\
82 \\
67 \\
48\end{array}$ & $\begin{array}{l}\text { Prevenar } 13 \\
\text { Prevnar } 13 \\
\text { How often pneumonia shot } \\
\text { Pneumo } 13 \\
\text { Prevenar } 13 \text { vacuna }\end{array}$ & Breakout \\
\hline Meningococcal Vaccine & $\begin{array}{l}\text { Australia } \\
\text { Brazil } \\
\text { Greece } \\
\text { Portugal } \\
\text { USA }\end{array}$ & $\begin{array}{l}100 \\
88 \\
84 \\
67 \\
62\end{array}$ & $\begin{array}{l}\text { Meningitis } \\
\text { Meningitis vaccine } \\
\text { Meningococcal } \\
\text { Meningococcal vaccine } \\
\text { Vacina }\end{array}$ & $\begin{array}{l}100 \\
94 \\
74 \\
59 \\
42\end{array}$ & $\begin{array}{l}\text { Vacina meningite } b \\
\text { Vacina acwy } \\
\text { Meningo } b \\
\text { Vacina meningite acwy } \\
\text { Meningo b vacina }\end{array}$ & Breakout \\
\hline
\end{tabular}

four notable spikes in search volume throughout the past 12 years. On further investigation, these spikes coincided with news events at those times.

In October 2012, there was an outbreak of fungal meningitis associated with the New England Compounding Center (NECC) in the United States. It was found that the NECC has been compounding injections of steroids contaminated with Exserohilum rostratum and Aspergillus fumigatus [15].

February 2016 was an eventful month due to overlapping international events. First, there was a large outbreak of pneumococcal and meningococcal meningitis in Ghana [16]. Second, there was likewise a spike of cases in Tuscany, Italy during a meningitis epidemic that has been ongoing since 2015 [17]. At the same

Table 3 Spearman rank correlations between the SVI of meningitis, its related vaccinations, and worldwide number of cases

\begin{tabular}{llc}
\hline Variable & $\begin{array}{l}\text { Spearman rank } \\
\text { coefficient }\end{array}$ & $\boldsymbol{P}$-value \\
\hline Pneumococcal vaccine & 0.011 & 0.895 \\
Influenza vaccine & 0.051 & 0.526 \\
BCG vaccine & 0.369 & $<0.001^{*}$ \\
Meningococcal vaccine & 0.183 & $0.022^{*}$ \\
Worldwide number of cases & 0.354 & 0.179 \\
\hline
\end{tabular}

SVI Search volume index time in the United Kingdom, the daughter of Matt Dawson, a British professional football player, died of meningococcal meningitis [18]. This spurred a petition to make meningococcal vaccinations mandatory for children up to 11 years old. The petition gathered 823,349 signatures by its conclusion [19]. Meanwhile in the United States, there was an outbreak among students in Santa Clara University, California and likewise contributed to the interest in vaccination [20]. Unsurprisingly, the top three countries with the highest search interest in this period were Ghana, Italy, and the United Kingdom.

The peak in January 2017 was caused mainly by searches coming from Italy. While this interest was not due to increasing cases, there was a highly publicized shift in the policies of local health authorities that strengthened vaccine coverage and allowed substantial savings up to $50 \%$ with the assistance of insurance [21]. This announcement was made on December 29, 2016 and media coverage lasted up to May 2017.

Finally, the most recent spike occurred in March 2019. This was when former Brazilian president Luiz Inacio Lula da Silva, who was imprisoned for corruption allegations, was given temporary leave to attend his grandson's funeral who died of meningitis [22]. Both the prison furlough and funeral garnered media attention. 
These patterns show that traditional media such as television, radio, and newsprint still have a role in disseminating health information. These media can serve as gateways to information and spur further health-seeking behavior at the user's own time and convenience. In order to have a successful public health information policy, both traditional media and the internet must be used together.

The present analysis showed that while there were statistically significant correlations between meningitis and the BCG and meningococcal vaccines; the relationships appeared weak. It was also unclear if these correlations correspond to the overall decrease in meningitis cases worldwide. There were no correlations seen with the other vaccines. There was clear seasonal interest in the influenza vaccine, but this was not observed in meningitis. Search interests in meningitis, therefore, do not appear to correlate with search interests on its vaccine or its number of cases.

Non-parametric Spearman correlation was chosen as case numbers of meningitis and search interest of the various keywords over the study period were hypothesized to be non-normally distributed. This was supported by this study's results as shown in Figs. 1 and 2 . Meningitis is a chronic global problem with multiple outbreaks and not a point epidemic hence an assumption of normality cannot be made. Similarly, search interest is expected to be non-normal as access to the internet is not uniform throughout the world and the global population is unlikely to be searching for the same topic within the same timeframe. As internet access varies throughout the world and different countries experience outbreaks at different times, the assumption of normality cannot likewise be made.

Testing for autocorrelation is also important since some of the vaccines of interest are seasonal in nature, such as with the influenza vaccine. Inspection of data showed a seasonal trend in the search interest for the influenza vaccine (see Fig. 1) and this is supported by the Durbin-Watson test which showed positive autocorrelation. The Durbin-Watson test is used in time-series analysis and helps differentiate if the seasonal trend is a natural sequential order or is due to some other external cause [12]. In the case of this analysis, the positively autocorrelated search interest in influenza vaccine is an inherent pattern and makes the overall correlation with meningitis more reliable.

Counterintuitively, these results are not entirely unexpected. As previously discussed, the internet may play a role in the sustenance of awareness and search interest in meningitis despite its decreasing numbers worldwide. As for the weak to absent correlations of meningitis with vaccines, it may be possible that the messaging of these vaccines is not clear as they relate to meningitis. Another possibility is that the other complications of tuberculosis and meningococcus such as disseminated TB or meningococcemia are emphasized. This means that meningitis alone may not be a sufficient surrogate measure for vaccine awareness and that other related illnesses must be investigated as well. Meningitis is not the only complication these vaccines prevent. For health workers who will undergo similar studies in the future, search terms must be selected holistically and should reflect the full spectrum of the disease to detect more nuanced correlations.

There were several limitations to this study. First, this study was confined to Google searches and did not measure search interest in social media. While there were spikes in search interest in meningitis, these were attributable to meningitis dominating news headlines. The extent of how specific social media platforms could have contributed to search interest is unknown. The study was also subject to the penetration of internet access as not all countries may have the same ability or extent to perform Google searches. In effect, this study was only able to measure the search behavior of those with internet access and may underrepresent resource-poor countries. Another limitation was that the Global Burden of Disease Database reports all-cause meningitis and does not differentiate among bacterial, viral, fungal, or tuberculous meningitis. Finally, there was a paucity of validated data on Google search behavior and other online behavior such as in social media. It is then difficult to establish true causality and relationships between search terms. The possible explanations discussed in this analysis are hypotheses that warrant further study.

While Google Trends ${ }^{\mathrm{TM}}$ results are increasingly being used to provide a general study of online search behavior, future infodemiological studies can focus on social media for a more precise and granular evaluation of internet behavior. Not only will these future studies use search data, but internet crawlers may be programmed to measure interactions and engagement, analyze semantics and even perform big data analytics for improvement of public health and policy.

\section{Conclusion}

The present study found weak correlations between Google SVIs for meningitis and the BCG and meningococcal vaccines without any correlations with worldwide meningitis cases. The majority of online search interest came from the developing countries with queries related to definitions, signs, and symptoms while developed countries searched for vaccine information. Worldwide search interest was increasing despite decreasing numbers of meningitis globally. Despite the weak correlations found, this study serves as a step towards more complex 
and robust infodemiological studies in the future. Given the relative youth of the field of infodemiology, its methods may still be further refined and its limitations overcome. The internet plays a significant role in medicine hence infodemiology will continue to grow as an emerging tool towards better public health and healthcare.

\section{Abbreviations}

COVID-19: Coronavirus disease; GHDx: Global Health Data Exchange Database; NECC: New England Compounding Center; SVI: Search volume index.

\section{Acknowledgements}

Not applicable.

\section{Authors' contributions}

JALSP: Conceptualization, data curation, formal analysis, interpretation of data, writing-original draft, writing-review, and editing. AIE: Conceptualization, data curation, formal analysis, interpretation of data, writing-original draft, writingreview, and editing. RDGJ: Conceptualization, data curation, formal analysis, interpretation of data, writing-original draft, writing-review, and editing. The authors read and approved the final manuscript.

\section{Funding}

This research did not receive any specific grant from funding agencies in the public, commercial, or not-for-profit sectors.

\section{Availability of data and materials}

The datasets used and/or analyzed during the current study are available from the corresponding author on reasonable request.

\section{Declarations}

Ethics approval and consent to participate

Not applicable.

\section{Consent for publication}

Not applicable.

\section{Competing interests}

The authors declare that they have no competing interests.

\section{Author details}

'Institute for Neurosciences, St. Luke's Medical Center, Quezon City \& Global City, Philippines. ${ }^{2}$ Department of Clinical Epidemiology, College of Medicine, University of the Philippines Manila, Manila, Philippines. ${ }^{3}$ Department of Neurosciences, College of Medicine, Philippine General Hospital, University of the Philippines Manila, Manila, Philippines.

Received: 12 February 2021 Accepted: 24 May 2021

Published online: 23 June 2021

\section{References}

1. GBD 2016 Meningitis Collaborators. Global, regional, and national burden of meningitis, 1990-2016: a systematic analysis for the Global Burden of Disease Study 2016. Lancet Neurol. 2018;17(12):1061-82. https://doi.org/ 10.1016/S1474-4422(18)30387-9.

2. World Health Organization. Meningococcal meningitis - Key Facts. 2018. https://www.who.int/en/news-room/factsheets/detail/menin gococcal-meningitis. Accessed 11 Mar 2021.

3. Daugla DM, Gami JP, Gamougam K, Naibei N, Mbainadji L, Narbe M, et al. Effect of a serogroup A meningococcal conjugate vaccine (PsA - TT) on serogroup A meningococcal meningitis and carriage in Chad: a community study. Lancet. 2014;383(9911):40-7. https://doi.org/10.1016/S01406736(13)61612-8

4. Mavragani A. Infodemiology and infoveillance: scoping review. J Med Internet Res. 2020;22(4):1-15. https://doi.org/10.2196/16206.

5. Ling R, Lee J. Disease monitoring and health campaign evaluation using Google search activities for HIV and AIDS, stroke, colorectal cancer, and marijuana use in Canada: a retrospective observational study. JMIR Public Heal Surveill. 2016;2(2): e156. https://doi.org/10.2196/publichealth.6504.

6. Kim H, Xie B. Health literacy in the eHealth era: a systematic review of the literature. Patient Educ Couns. 2017;100(6):1073-82. https://doi.org/10. 1016/j.pec.2017.01.015.

7. Handy LK, Maroudi S, Powell M, et al. The impact of access to immunization information on vaccine acceptance in three countries. PLoS ONE. 2017;12(8):1-16. https://doi.org/10.1371/journal.pone.0180759.

8. Eysenbach G. Infodemiology and infoveillance: framework for an emerging set of public health informatics methods to analyze search, communication and publication behavior on the Internet. J Med Internet Res. 2009;11(1):1-10. https://doi.org/10.2196/jmir.1157.

9. Nuti SV, Wayda B, Ranasinghe I, Wang S, Dreyer RP, Chen SI, et al. The use of google trends in health care research: a systematic review. PLoS One. 2014;9(10):e109583. https://doi.org/10.1371/journal.pone.0109583.

10. Cervellin G, Comelli I, Lippi G. Is Google Trends a reliable tool for digital epidemiology? Insights from different clinical settings. J Epidemiol Glob Health. 2017;7(3):185-9. https://doi.org/10.1016/j.jegh.2017.06.001.

11. Global Burden of Disease Collaborative Network. Global Burden of Disease Study 2019 (GBD 2019) Results. Institute for Health Metrics and Evaluation. 2020. http://ghdx.healthdata.org/gbd-results-tool. Accessed 25 Dec 2020.

12. Chatterjee S, Simonoff JS. Handbook of Regression. Analysis. 2013. https://doi.org/10.1002/9781118532843.

13. Bragazzi NL. Infodemiology and infoveillance of multiple sclerosis in Italy. Mult Scler Int. 2013;2013:1-9. https://doi.org/10.1155/2013/924029.

14. Brigo F, Trinka E. Google search behavior for status epilepticus. Epilepsy Behav. 2015;49:146-9. https://doi.org/10.1016/j.yebeh.2015.02.029.

15. US CDC. Multistate Meningitis Outbreak. 2015. https://www.cdc.gov/hai/ outbreaks/meningitis.html. Accessed 25 Dec 2020.

16. Aku FY, Lessa FC, Asiedu-Bekoe F, Balagumyetime P, Ofosu W, Farrar J, et al. Meningitis outbreak caused by vaccine-preventable bacterial pathogens - Northern Ghana 2016. MMWR Mortal Wkly Rep. 2017;66(30):806-10. https://doi.org/10.15585/mmwr.mm6630a2.

17. Stefanelli P, Miglietta A, Pezzotti P. Increased incidence of invasive meningococcal disease of serogroup C/clonal complex 11, Tuscany, Italy, 2015 to 2016. Eurosurveillance. 2016;21(12). https://doi.org/10.2807/15607917.ES.2016.21.30176.

18. BBC News. Matt Dawson reveals "two weeks of hell" over son's meningitis. Published 2016. https://www.bbc.com/news/ukengland-london-35602 045. Accessed 26 Dec 2020.

19. UK Government and Parliament. Give the meningitis B vaccine to ALL children, not just newborn babies. 2016. Accessed 26 Dec 2020. https:// petition.parliament.uk/archived/petitions/108072

20. Veklerov K. Meningitis-linked bacteria hits 3rd Santa Clara University student. SFGate. 2016. https://www.sfgate.com/bayarea/article/Outbr eak-of-meningitis-causing-bacteria-hits-3rd-6807744.php. Accessed 26 Dec 2020.

21. Covolo L, Croce E, Moneda M, Zanardini E, Gelatti U, Schulz PJ, et al. Meningococcal disease in Italy: public concern, media coverage and policy change. BMC Public Health. 2019;19:1061. https://doi.org/10.1186/ s12889-019-7426-5.

22. BBC News. Lula back in Brazil prison after grandson's funeral. 2019. https://www.bbc.com/news/world-latin-america-47424066. Accessed 25 Dec 2020.

\section{Publisher's Note}

Springer Nature remains neutral with regard to jurisdictional claims in published maps and institutional affiliations. 